\title{
Biodegradation of the Polycyclic Aromatic Hydrocarbon Fluoranthene by Fungi Strains from a Brazilian Tropical Peat
}

\author{
Anuska C. F. S. Garcia, ${ }^{\circledR a}$ Willian G. Birolli, ${ }^{\odot b, c}$ Bruno R. Araújo, ${ }^{\circledR a}$ Carla G. Marques, ${ }^{\circledR d}$ \\ Antônio M. Barbosa-Junior, ${ }^{\circledR e}$ Leandro E. C. Diniz, ${ }^{\oplus f}$ André L. M. Porto ${ }^{\circledR *, b}$ and \\ Luciane P. C. Romão ${ }^{\odot *, a}$ \\ ${ }^{a}$ Laboratório de Estudos da Matéria Orgânica Natural, Departamento de Química, \\ Universidade Federal de Sergipe, 49100-000 São Cristóvão-SE, Brazil \\ ${ }^{b}$ Laboratório de Química Orgânica e Biocatálise, Instituto de Química de São Carlos, \\ Universidade de São Paulo, 13563-120 São Carlos-SP, Brazil \\ ${ }^{c}$ Centro de Ciências Exatas e de Tecnologia, Universidade Federal de São Carlos, \\ Via Washington Luiz, km 235, CP 676, 13565-905 São Carlos-SP, Brazil \\ ${ }^{d}$ Laboratório de Biodiversidade Molecular e Conservação, Departamento de Genética e Evolução, \\ Universidade Federal de São Carlos, 13565-905 São Carlos-SP, Brazil \\ ${ }^{e}$ Laboratório de Microbiologia Aplicada, Departamento de Morfologia, \\ Universidade Federal de Sergipe, 49100-000 São Cristóvão-SE, Brazil \\ ${ }^{f}$ Laboratório de Biologia Molecular, Empresa Brasileira de Pesquisa Agropecuária, \\ 49025-040 Aracaju-SE, Brazil
}

\begin{abstract}
Polycyclic aromatic hydrocarbons (PAHs) are an important environmental issue and the identification of new biocatalysts for an efficient biodegradation of these compounds is essential for bioremediation. Therefore, fungi strains isolated for the first time from a tropical peat at Santo Amaro das Brotas (Brazil) were studied for fluoranthene biodegradation. Fusarium sp. AC-7, Penicillium sp. AC-1 and Penicillium sp. AC-6 were isolated using fluoranthene as sole carbon source. All strains were tested for biodegradation of $100 \mathrm{mg} \mathrm{L}^{-1}$ fluoranthene during 14 and 28 days. After 28 days of biodegradation, $64 \pm 3,60 \pm 4$ and $51 \pm 2 \%$ biodegradation was observed for Penicillium sp. AC-1, Penicillium sp. AC-6 and Fusarium sp. AC-7, respectively. Analysis of the obtained compounds enabled the identification of four metabolites, which were common to the three employed strains: anthrone, anthraquinone, 9-methoxyanthracene and cyclopropa[1]phenanthrene. It is important to note that control experiments were performed. The obtained results clearly demonstrated the efficiency of tropical peat fungi in the transformation of fluoranthene. These findings showed the potential of tropical peats for isolation of fungi and indicated that these strains can be applied for bioremediation processes of areas contaminated with fluoranthene and other PAHs.
\end{abstract}

Keywords: peat, biotransformation, bioremediation, microorganism, metabolite, anthraquinone

\section{Introduction}

Polycyclic aromatic hydrocarbons (PAHs) are a class of aromatic fused-ring compounds produced by fossil fuel and biomass combustion, also, these compounds possess carcinogenic, mutagenic, and toxic properties. ${ }^{1}$ Moreover, these substances are ubiquitous environmental pollutants, and their low bioavailability and high hydrophobicity

*e-mail: almporto@iqsc.usp.br; lucianeromao@uol.com.br create difficulties to their treatment and elimination. ${ }^{2}$ The importance of minimizing the release of PAHs and the need to remove them from the environment resulted in the listing of 16 PAHs, including fluoranthene, as priority pollutants by the United States Environmental Protection Agency (USEPA). ${ }^{3}$

The majority of PAHs released in the environment are categorized as $2 \mathrm{~A}$ and $2 \mathrm{~B}$ carcinogens, categorizing these compounds as probable and possible carcinogenic agents, respectively. Moreover, these compounds produce acute and 
toxic effects promoting several heart and lung diseases. ${ }^{4}$ In addition, it is not possible to determine a safety limit of exposure to PAHs, since these compounds are genotoxic carcinogens, promoting deoxyribonucleic acid (DNA) alterations and mutations. ${ }^{5}$

Fluoranthene is a four-ring compound found in the environment and one of the major components of petroleum sludge. ${ }^{6-8}$ In addition, previous studies determined the levels of PAHs in the produced water of oilfields and showed that fluoranthene was one of the PAHs present at highest concentrations. ${ }^{9}$

The hazards associated with PAHs can be eliminated by different decontamination methods, including soil washing, electrokinetic phenomena, chemical oxidation, phytoremediation and bioremediation by microorganisms, depending on the pollutant concentration, site characteristics, costs, and other factors. ${ }^{10}$ However, it is important to note that many of these approaches are expensive, and in many cases they only transfer the pollutant of place, whereas bioremediation is an adequate tool for wide areas, transforming these compounds into less toxic metabolites with reduced input of chemicals, energy, and time. ${ }^{11}$

The use of microbial technology is a more efficient, economical, eco-friendly, and adaptable choice to treat PAHcontaminated sites, when compared to physicochemical treatments. ${ }^{12}$ However, it is necessary to find promising microorganisms capable of degrading hydrocarbons and promote efficient environmental decontamination. ${ }^{13}$

In recent years, the fungal ability to degrade highmolecular-weight xenobiotics had attracted attention due to the enzymatic predominance of multiplex pathways. ${ }^{14}$ In the literature, it was reported that fungi are more likely to attack these pollutants in soil than bacteria, since they possess the ability to diffuse in soil releasing extracellular enzymes. ${ }^{15,16}$ However, each case should be evaluated individually, since bacteria can also present interesting results for PAHs. ${ }^{17}$

Soil represents the largest global source of microbial diversity, and peats are one of the most promising type of soil for microorganism prospecting, because of its continuous and complex processes of decomposition and humification of plant residues by microbial oxidation. $^{18,19}$

Peatlands possess high environmental value and importance, leading the European Commission ${ }^{20}$ to consider these ecosystems as natural environments of priority interest for conservation, with emphasis to global carbon sequestration. Since their irrational draining for agricultural purposes transform these biomes in carbon sources that aggravate the greenhouse effect. ${ }^{21}$
Brazil possess approximately $1.6 \times 10^{9} \mathrm{~m}^{3}$ of peat resources distributed across more than 200 peatlands. ${ }^{22}$ In Sergipe, a Brazilian state, there are 21 peatlands with around 774 kton of peat (dry basis). The peat of Santo Amaro das Brotas in Sergipe has been studied in terms of its chemical composition and adsorption of organic and inorganic compounds. ${ }^{23-25}$

Peatlands are known to contain large microbial populations with a wide metabolic diversity, ${ }^{26}$ which can be explored for potential uses in biotechnological applications. Moreover, a bacterial strain Serratia sp. AC-11 from the peat of Santo Amaro das Brotas biodegraded 56\% fluoranthene in $24 \mathrm{~h}$, showing the potential of microorganisms from this peat for PAHs biodegradation. ${ }^{17}$

Therefore, the aim of this study was the isolation of fungi strains from the tropical peat at Santo Amaro das Brotas obtaining biocatalysts for fluoranthene biodegradation, also analyzing the produced metabolites for future bioremediation processes.

\section{Experimental}

Salts, reagents, solvents, and culture media

Fluoranthene (98\%) was acquired from Sigma-Aldrich (São Paulo, Brazil) and anthracene (99\%) from Across Organics (New Jersey, USA). The employed salts ( $\mathrm{KCl}$, $\mathrm{KH}_{2} \mathrm{PO}_{4}, \mathrm{Na}_{2} \mathrm{HPO}_{4}, \mathrm{NH}_{4} \mathrm{NO}_{3}, \mathrm{MgSO}_{4}, \mathrm{FeSO}_{4}, \mathrm{MnCl}_{2}, \mathrm{CaCl}_{2}$ ) and ethyl acetate were obtained from Synth (Diadema, São Paulo, Brazil). Whereas, agar, malt extract and Sabouraud medium were purchased from Himedia (Mumbai, India). The TaqDNA polymerase and others molecular supplies were obtained from Invitrogen (Waltham, Massachusetts, USA) and Integrated DNA Technologies (Coralville, Iowa, USA).

\section{Peat soil collection}

Approximately $1 \mathrm{~kg}$ of peat was collected from Santo Amaro das Brotas peatland, State of Sergipe, Brazil, $2^{\text {nd }}$ April 2013 (1048'39' S, 36 58'23' W). The soil was collected from $5-20 \mathrm{~cm}$ deep and stored in a sterile glass bottle at $4{ }^{\circ} \mathrm{C}$. The physicochemical properties: $\mathrm{pH}$, organic matter, cation exchange capacity, calcium, magnesium, aluminum, sodium, potassium, phosphorus, copper, manganese, and zinc were determined according to standard procedures. ${ }^{27}$

\section{Fungi isolation}

The fungi strains were isolated as described previously with modifications. ${ }^{28} \mathrm{~A} 1.0 \mathrm{~mL}$ aliquot of soil suspension was 
inoculated into $9.0 \mathrm{~mL}$ of liquid mineral medium composed of $0.7 \mathrm{~g} \mathrm{~L}^{-1} \mathrm{KCl}, 2.0 \mathrm{~g} \mathrm{~L}^{-1} \mathrm{KH}_{2} \mathrm{PO}_{4}, 3.0 \mathrm{~g} \mathrm{~L}^{-1} \mathrm{Na}_{2} \mathrm{HPO}_{4}$ and $1.0 \mathrm{~g} \mathrm{~L}^{-1} \mathrm{NH}_{4} \mathrm{NO}_{3}$. The mineral medium was supplemented with $1 \mathrm{~mL} \mathrm{~L}^{-1}$ of a micronutrients solution composed of $4.0 \mathrm{~g} \mathrm{~L}^{-1} \mathrm{MgSO}_{4}, 0.2 \mathrm{~g} \mathrm{~L}^{-1} \mathrm{FeSO}_{4}, 0.2 \mathrm{~g} \mathrm{~L}^{-1} \mathrm{MnCl}_{2}$, $0.2 \mathrm{~g} \mathrm{~L}^{-1} \mathrm{CaCl}_{2}$ and $100 \mathrm{mg} \mathrm{L}^{-1}$ of fluoranthene as sole carbon and energy source. The cultures were incubated at $32{ }^{\circ} \mathrm{C}$ and $150 \mathrm{rpm}$ for 7 days. After this, the spreading plate technique was performed employing Sabouraud agar medium. The purified isolates were kept at $4{ }^{\circ} \mathrm{C}$ in test tubes with Sabouraud agar.

\section{Extraction of DNA from fungi}

The isolates were identified by partial sequencing of the $18 \mathrm{~S}$ ribosomal ribonucleic acid (rRNA) genes. The genomic DNA was extracted from each culture using a NucleoSpin Plant II kit from Macherel-Negel (Bethlehem, Pennsylvania, USA) following the manufacturer's instructions.

The polymerase chain reaction (PCR) was conducted using oligonucleotides corresponding to the ITS 1 (5'-TCCGTAGGTGAACCTGCGG-3') and ITS 4 (5'-TCCTCCGCTTATTGATATGC-3') universal primers. The reactions were prepared with $2 \mu \mathrm{L}$ of DNA $\left(30 \mathrm{ng} \mu \mathrm{L}^{-1}\right)$ and $48 \mu \mathrm{L}$ of the PCR mix, composed of $5 \mu \mathrm{L}$ of $10 \mathrm{X}$ buffer, $3 \mu \mathrm{L}$ of $\mathrm{MgCl}_{2}(50 \mathrm{mM}), 1 \mu \mathrm{L}$ of deoxynucleotide (dNTP's, $2.5 \mathrm{mM}), 1 \mu \mathrm{L}$ of each primer $(10 \mathrm{mM}), 0.2 \mu \mathrm{L}$ of Taq DNA

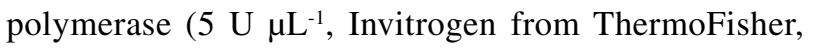
Waltham, Massachusetts, USA), and $36.8 \mu \mathrm{L}$ of sterile deionized water. The amplification was carried out as following, one cycle at $95{ }^{\circ} \mathrm{C}$ for $5 \mathrm{~min}, 40$ cycles at $94{ }^{\circ} \mathrm{C}$ for $60 \mathrm{~s}, 60^{\circ} \mathrm{C}$ for $60 \mathrm{~s}, 72^{\circ} \mathrm{C}$ for $60 \mathrm{~s}$, and a final extension step at $72^{\circ} \mathrm{C}$ for $5 \mathrm{~min}$. The PCR products were analyzed by electrophoresis, purified using a GE Healthcare kit (Chicago, United States), and then sequenced at the sequencing service of São Paulo University.

\section{Nucleotide sequencing and phylogenetic analyses}

The forward nucleotide sequences were determined using a BigDye Terminator Cycle Sequencing Kit v.3.1 and an automated ABI 3730 DNA Analyzer (Applied Biosystems, Waltham, USA). The sequences were viewed, edited, and aligned using the software Geneious v.6.1.8. ${ }^{29}$ Nuclear mitochondrial DNA (NUMT) and stop codons were absent in all the sequences. Homology searches were performed with the BLAST/NCBI software and Neighbor-Joining trees were constructed in the software MEGA v. $6.0^{30}$ using p-distance, complete deletion, and bootstrapping with 1000 replications. The sequences were deposited at GenBank, Penicillium sp. AC-1 accession number KP264566, Penicillium sp. AC-6 accession number KP264567, and Fusarium sp. AC-7 accession number KP264568.

\section{Biodegradation assays}

The fungal growth and biodegradation experiments were performed as described previously with modifications. ${ }^{31}$ The fungi strains were grown for 7 days at $32{ }^{\circ} \mathrm{C}$ in $2 \%$ malt extract agar in the presence of $100 \mathrm{mg} \mathrm{L}^{-1}$ fluoranthene. Subsequently, seven mycelia discs ( $5 \mathrm{~mm}$ diameter) were inoculated into $50 \mathrm{~mL}$ of $2 \%$ malt extract medium and cultivated for 5 days at $32{ }^{\circ} \mathrm{C}$ in an orbital shaker $(130 \mathrm{rpm})$.

After incubation, the liquid medium containing the fungal mycelia was supplemented with $100 \mathrm{mg} \mathrm{L}^{-1}$ of fluoranthene and the mixture was incubated in an orbital shaker (at $130 \mathrm{rpm}$ and $32{ }^{\circ} \mathrm{C}$ ) for 14 and 28 days. All the experiments were carried out in triplicate.

After biodegradation, the culture was filtered in a Buchner apparatus yielding the supernatant solution-1. In addition, the mycelial mass was suspended in $30 \mathrm{~mL}$ of a water and ethyl acetate mixture (1:1), and magnetic stirred during $30 \mathrm{~min}$ for extraction, and then filtered again using a Buchner funnel, providing the supernatant solution-2. The mycelia dry weight was determined after drying at $32{ }^{\circ} \mathrm{C}$ for 5 days.

The supernatant solution from the liquid medium (solution-1) and the mycelium extraction (solution-2) were put together and transferred to an Erlenmeyer flask. The $\mathrm{pH}$ of the solution was adjusted to 7.0 and a liquidliquid partition was performed. Then, more two steps of extraction with $30 \mathrm{~mL}$ ethyl acetate were carried out. After separation, the organic phase was dried with anhydrous $\mathrm{Na}_{2} \mathrm{SO}_{4}$, filtered, and evaporated under reduced pressure. The residue was resuspended in $5 \mathrm{~mL}$ of ethyl acetate and analyzed by chromatographic techniques.

Controls without the addition of fluoranthene were performed for determination of the natural products of the fungal metabolism. Moreover, abiotic control experiments with the addition of $100 \mathrm{mg} \mathrm{L}^{-1}$ of fluoranthene in $50 \mathrm{~mL}$ of $2 \%$ malt medium without the inoculation of fungi were carried out for 28 days to assess the substrate stability in the employed conditions.

The method recovery was determined in three cultures of Penicillium sp. AC- 1 cultivated for 5 days at $32{ }^{\circ} \mathrm{C}$ and $130 \mathrm{rpm}$, which were sterilized in autoclave $\left(121^{\circ} \mathrm{C}\right.$, $20 \mathrm{~min}, 2 \mathrm{~atm})$. Then, the addition of $100 \mathrm{mg} \mathrm{L}^{-1}$ was performed, followed by orbital stirring at $130 \mathrm{rpm}$ for $30 \mathrm{~min}$, and subsequently extracted for fluoranthene determination. 
Determination of fluoranthene degradation using GC-FID and its metabolites identification by GC-MS

All biodegradation experiments were analyzed using a Shimadzu (Tokyo, Japan) GC 2010 gas chromatograph (GC) equipped with an AOC 20i auto-injector, a flame ionization detector (FID), and a DB5 column (J\&W Scientific, $30 \mathrm{~m} \times 0.25 \mathrm{~mm} \times 0.25 \mu \mathrm{m})$. The oven program was $100^{\circ} \mathrm{C}$ for $1 \mathrm{~min}$, followed by a temperature increase at $8^{\circ} \mathrm{C} \min ^{-1}$ up to $280{ }^{\circ} \mathrm{C}$, which was maintained for $7.5 \mathrm{~min}$. Split ratio of 5 was used, and the injector temperature was $250{ }^{\circ} \mathrm{C}$. The quantification was performed using anthracene as internal standard. ${ }^{26}$

The analysis of metabolites from fluoranthene biodegradation was performed by gas chromatographymass spectrometry (GC-MS) using a Shimadzu (Tokyo, Japan) GC-2010 Plus gas chromatograph coupled to a mass selective detector (Shimadzu MS-2010 Plus), which was operated in electron ionization at $70 \mathrm{eV}$ in SCAN mode $m / z$ 40-500. The GC-MS was equipped with a DB5 column (J\&W Scientific, $30 \mathrm{~m} \times 0.25 \mathrm{~mm} \times 0.25 \mu \mathrm{m}$ ). The oven program was $90{ }^{\circ} \mathrm{C}$ for $2 \mathrm{~min}$, followed by a temperature increase at $6{ }^{\circ} \mathrm{C} \mathrm{min}^{-1}$ up to $280{ }^{\circ} \mathrm{C}$, which was maintained for $6.33 \mathrm{~min}$. A split ratio of 5 was used, the injector temperature was $250{ }^{\circ} \mathrm{C}$, and the interface temperature was $270{ }^{\circ} \mathrm{C}$. Metabolites identification was carried out using NIST 08, 08s, 21, and 107, and Wiley 8 Mass Spectra Libraries. ${ }^{32}$

\section{Results and Discussion}

\section{Physicochemical characterization of the peat soil}

The physicochemical characterization of the peat soil was summarized in Table 1. The chemical composition of organic soils is determined by the nature and rate of organic matter decomposition, and the minerals of the water. ${ }^{33} \mathrm{~A}$ peat soil is classified as a histosol due to its high content of organic matter ( $>80 \mathrm{mg} \mathrm{kg}^{-1}$ ) and low $\mathrm{pH}$. The $\mathrm{pH}$ value of the water obtained in this study was in agreement with the data reported in the literature $(\mathrm{pH}$ 2.7-4.4), which showed that its acid character was due to the presence of humic and fulvic acids. ${ }^{19}$

The concentrations of $\mathrm{Mg}^{2+}$ and $\mathrm{Na}^{+}$found in the peat sample was higher than that of $\mathrm{Ca}^{2+}$ and $\mathrm{K}^{+}$, respectively (Table 1). As previous suggested, this effect may be related to the proximity to coastal areas and tidal influence in the sediments. ${ }^{33}$

Peatlands are typically divided into ombrotrophic bogs, which have low nutrient availability because they are exclusively fed by atmospheric precipitation, and
Table 1. Physicochemical characterization from the peatland of Santo Amaro das Brotas, State of Sergipe, Brazil

\begin{tabular}{lc}
\hline Parameter & Data \\
\hline $\mathrm{pH}$ & 4.1 \\
Organic matter $/\left(\mathrm{g} \mathrm{dm}^{-3}\right)$ & 80.7 \\
Cation exchange capacity / $\left(\mathrm{cmol}_{\mathrm{c}} \mathrm{dm}^{-3}\right)$ & 9.68 \\
$\mathrm{Ca}^{2+} /\left(\mathrm{cmol}_{\mathrm{c}} \mathrm{dm}^{-3}\right)$ & 0.95 \\
$\mathrm{Mg}^{2+} /\left(\mathrm{cmol}_{\mathrm{c}} \mathrm{dm}^{-3}\right)$ & 1.61 \\
$\mathrm{Al}^{3+} /\left(\mathrm{cmol}_{\mathrm{c}} \mathrm{dm}^{-3}\right)$ & 1.88 \\
$\mathrm{Na}^{+} /\left(\mathrm{mg} \mathrm{dm}^{-3}\right)$ & 42.9 \\
$\mathrm{~K}^{+} /\left(\mathrm{mg} \mathrm{dm}^{-3}\right)$ & 25.2 \\
$\mathrm{P}^{-(}\left(\mathrm{mg} \mathrm{dm}^{-3}\right)$ & 3.0 \\
$\mathrm{Fe}^{2+} /\left(\mathrm{mg} \mathrm{dm}^{-3}\right)$ & 19.17 \\
$\mathrm{Cu}^{2+} /\left(\mathrm{mg} \mathrm{dm}^{-3}\right)$ & 0.09 \\
$\mathrm{Mn}^{2+} /\left(\mathrm{mg} \mathrm{dm}^{-3}\right)$ & 2.77 \\
$\mathrm{Zn}^{2+} /\left(\mathrm{mg} \mathrm{dm}^{-3}\right)$ & 1.54 \\
\hline
\end{tabular}

$\mathrm{cmol}_{\mathrm{c}} \mathrm{dm}^{-3}$ : load centimole for cubic decimeter.

minerotrophic fens, which receive water and nutrients from precipitation and local groundwater, presenting higher nutrient availability and consequently greater biomass productivity. ${ }^{34}$

The peat soil from Santo Amaro das Brotas is minerotrophic, containing high levels of some micronutrients $\left(\mathrm{Mg}^{2+}, \mathrm{Na}^{+}, \mathrm{K}^{+}, \mathrm{Fe}^{2+}, \mathrm{Mn}^{2+}\right.$, and $\mathrm{Zn}^{2+}$ ) because of groundwater supply (Table 1). Nutrient-rich peat soils are known to contain a large microbial population with wide metabolic diversity, ${ }^{25}$ which are interesting properties for isolation of efficient strains for the biodegradation of environmental contaminants as fluoranthene.

Isolation and identification of fungi from peat soil

The search for new sources of microorganisms with biodegradation potential is growing worldwide for bioremediation of contaminated environments. ${ }^{35}$ Three fungal strains were isolated using fluoranthene as sole carbon and energy source, showing potential for biodegradation of this organic pollutant. Therefore, the peat from Santo Amaro das Brotas is a potential source of PAH-degrading fungi.

The three isolated strains were identified as Penicillium strains AC-1 (GenBank KP264566) and AC-6 (GenBank KP264567), and Fusarium AC-7 (GenBank KP264568). These strains showed high similarities with more than one species during identification, thus it was not possible to identify them at the species level with the employed identification method.

All the identified genera have been reported in the literature as potential candidates for the biodegradation of PAHs. However, this is the first time that fungal strains 
were isolated from Santo Amaro das Brotas peat aiming at biodegradation of these compounds.

Penicillium species were studied for PAHs biodegradation, e.g., Penicillium oxalicum HM469410 completely biodegraded anthracene and dibenzothiophene in $2 \%$ soybean flour suspension for 4 days $\left(28{ }^{\circ} \mathrm{C}\right.$, $120 \mathrm{rpm}$ and $100 \mu \mathrm{M}$ of initial concentration), ${ }^{36}$ and Penicillium simplicissimum CECT 20706 biodegraded 86\% anthracene in solid cork medium $\left(60 \%\right.$ humidity, $28{ }^{\circ} \mathrm{C}$, $0.46 \mathrm{mg} \mathrm{g}^{-1}$ of initial concentration) after 61 days. $^{37}$

In addition, strains of Fusarium solani isolated from a mangrove were used for biodegradation of $40 \%$ anthracene and $60 \%$ benz $[a]$ anthracene after 40 days, employing 50 and $20 \mathrm{mg} \mathrm{L}^{-1}$ of initial concentration, respectively, in mineral salt medium. ${ }^{38}$ Also, Fusarium sp. ZH-H2 from soil biodegraded different high molecular weight PAHs, including $91 \%$ of benzo[ $k]$ fluoranthene and $85 \%$ of benzo[a]anthracene after 7 days at $30{ }^{\circ} \mathrm{C}, 150 \mathrm{rpm}$ and $10 \mathrm{mg} \mathrm{L}^{-1}$ of PAH initial concentration in mineral medium. ${ }^{39}$

PAH-degrading microorganisms have been isolated from hydrocarbon-contaminated soils. However, this study shows that sites specialized in the decomposition of organic matter such as peats can also be a source of microorganisms for biodegradation processes of PAHs.

Fluoranthene biodegradation by fungal strains isolated from peat soil

The ability of fungi isolates from peat soil to biodegrade fluoranthene in a liquid medium for 14 and 28 days was evaluated (Figure 1). The biodegradation of fluoranthene by the fungal strains increased according to the reaction period, e.g., $27 \pm 1$ and $64 \pm 3 \%$ biodegradation for Penicillium sp. AC- 1 after 14 and 28 days, respectively. In the literature, ${ }^{8}$ different authors reported that PAHs degradation in

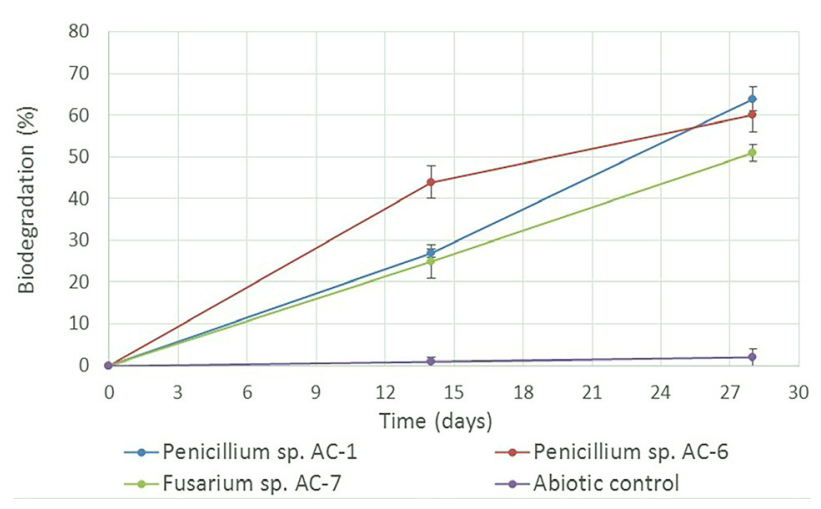

Figure 1. Fluoranthene biodegradation by fungal strains isolated from soil of a Brazilian peat for 14 and 28 days $\left(32{ }^{\circ} \mathrm{C}, 130 \mathrm{rpm}, 100 \mathrm{mg} \mathrm{L}^{-1}\right.$ of initial fluoranthene concentration). The presented values are the means, and the bars represent standard deviations of three replicates. percentage increases after longer biodegradation periods, although the biodegradation rate decreases. For fungi strains from Santo Amaro das Brotas, the biodegradation rate was constant until 28 days.

The hydrophobicity of fluoranthene reduce the bioavailability of the substrate, limiting its biodegradation. However, it is likely that polar groups are introduced into the fluoranthene molecule by extracellular enzymes, such as lignin peroxidases, laccases, manganese peroxidases and cytochrome P450, which catalyze oxidation reactions. ${ }^{7,40}$

The more efficient strain in the biodegradation of fluoranthene was Penicillium sp. AC-1, which was able to degrade $64 \pm 3 \%$ of fluoranthene after 28 days of incubation, while Penicillium sp. AC-6 and Fusarium sp. AC-7 strains degraded $60 \pm 4$ and $51 \pm 2 \%$, respectively. Significant fluoranthene depletion $(>26 \%$ ) was achieved by the strains after 14 days of incubation, but longer incubation periods increased PAH biodegradation. Therefore, the employed Penicillium strains were more efficient than the evaluated Fusarium sp. AC-7.

A simplified method validation of the fluoranthene determination was performed in order to ensure the quality of the analyses. For $50 \mathrm{mg} \mathrm{L}^{-1}$ of concentration, an average value of $48 \pm 2 \mathrm{mg} \mathrm{L}^{-1}$ was obtained for triplicate measurements, representing an accuracy of $96 \%$ and a precision of $4 \%$.

Additionally, an abiotic control (liquid medium without microorganism inoculation) was used as a blank control to determine a possible degradation by physicochemical events during the incubation period. Fluoranthene depletion of $1 \pm 1 \%$ was observed in the liquid medium after 10 days of incubation, while a reduction of $2 \pm 1 \%$ was determined in malt medium after 28 days of reaction without biocatalysts, showing that abiotic degradation was not significant in the employed experimental conditions.

Fungal strains have been explored in the biodegradation of PAHs, more specifically fluoranthene, with interesting results. For example, aerobic biodegradation reached $95 \%$ of $30 \mathrm{mg} \mathrm{L}^{-1}$ fluoranthene after 14 days in malt medium by Peniophora incarnata KUC10395. ${ }^{41}$ Moreover, up to $99 \%$ biodegradation of $100 \mathrm{mg} \mathrm{L}^{-1}$ fluoranthene after 10 days in malt medium by Dentipellis sp. KUC8613, ${ }^{42}$ and $57 \%$ biodegradation of $100 \mathrm{mg} \mathrm{L}^{-1}$ fluoranthene after 14 days in malt extract medium by the marine fungus Cladosporium sp. CBMAI1237 were described. ${ }^{31}$

In addition, the mycelial dry weight was obtained for the biodegradation experiments and fungal controls (experiment in the absence of fluoranthene) for both reaction periods (Table 2). 
Table 2. Growth of fungi from a Brazilian peat in presence of fluoranthene

\begin{tabular}{|c|c|c|c|c|c|c|}
\hline \multirow{2}{*}{ Reaction period } & \multicolumn{2}{|c|}{ Penicillium sp. AC-1 } & \multicolumn{2}{|c|}{ Penicillium sp. AC-6 } & \multicolumn{2}{|c|}{ Fusarium sp. AC-7 } \\
\hline & Control weight ${ }^{\mathrm{a}} / \mathrm{mg}$ & Weight $^{\mathrm{b}} / \mathrm{mg}$ & Control weight ${ }^{\mathrm{a}} / \mathrm{mg}$ & Weight $/ \mathrm{mg}$ & Control weight ${ }^{\mathrm{a}} / \mathrm{mg}$ & Weight $/ \mathrm{mg}$ \\
\hline 14 days & 650 & $620 \pm 10$ & 650 & $560 \pm 40$ & 610 & $520 \pm 60$ \\
\hline 28 days & 1090 & $780 \pm 120$ & 880 & $680 \pm 10$ & 560 & $550 \pm 50$ \\
\hline Inhibition for 14 days / \% & 5 & & 14 & & 15 & \\
\hline Inhibition for 28 days / $\%$ & 28 & & 23 & & 2 & \\
\hline
\end{tabular}

${ }^{a}$ Weight of fungus in absence of fluoranthene (control experiment); ${ }^{b}$ weight of fungus in the presence of fluoranthene (biodegradation process).

The fungal dry weight decreased in the presence of fluoranthene in comparison with the control experiment for all the three evaluated strains, indicating a toxicity and/or growth inhibition on the fungal cells. The strain Penicillium sp. AC-1, which was the most efficient strain for fluoranthene biodegradation, was the most inhibited strain for 28 days with $28 \%$ reduction in the mycelial weight. For Penicillium sp. AC-6 and Fusarium sp. AC-7, 23 and 2\% inhibition were determined, respectively.

Similar effects of inhibition in the mycelial mass were also reported in the biodegradation of organophosphate pesticides. The authors suggested that the microorganisms may have absorbed the substrate followed by its biotransformation as a defense response mechanism, which can cause subsequent cellular death due to the toxicity of phenolic metabolites, consequently reducing the fungal dry mycelial mass. ${ }^{43}$

It is important to note that although the occurrence of growth inhibition in a comparison to the fungal controls, there was an increase in the dry mycelial mass after 28 days when compared to the amount obtained after 14 days for the Penicillium strains. This increased mass confirmed that even in the presence of fluoranthene in the liquid medium, the two fungal strains were able to continue developing for longer incubation periods. This could have been one of the factors that contributed to greater fluoranthene biodegradation in the longer period (Table 2).

These data indicated that considering the recalcitrance of fluoranthene, the achieved biodegradation by fungi isolated from the peat of Santo Amaro das Brotas presented interesting results and should be employed in future PAHs bioremediation studies.

\section{Metabolites identification}

Most knowledge on catabolic pathways of fluoranthene biodegradation and the corresponding metabolites were obtained by bacteria. ${ }^{44,45}$ Therefore, a reduced number of studies were carried out using fungi strains ${ }^{46,47}$ Herein, our study focused in the metabolites obtained in the biodegradation by the fungal strains to determine a pattern of fluoranthene biodegradation related to the peatland environment.
The metabolites of the biodegradation process were analyzed and identified by GC-MS. Fungi cultures in the absence of fluoranthene were performed to differentiate the natural metabolites from those resulted from the PAH and, by comparison of the obtained chromatograms in the presence and absence of fluoranthene, it was possible to identify peaks corresponding to biodegradation metabolites. The metabolites were common to the three fungi strains and were absent in the abiotic and fungus control experiments.

The analyses of metabolites revealed the presence of compounds related to the fungi natural metabolism, such as fatty acids, alcohols, ketones and aldehydes (data not shown). This information was confirmed in the control experiments without the addition of fluoranthene. Among these compounds, five of them were related to the fluoranthene biodegradation, cyclopropa $[l]$ phenanthrene, 9-methoxyanthracene, anthrone, anthraquinone, and bis(6-methylheptyl)phthalate (Table 3).

There are two main types of PAHs fungal metabolism, the non-ligninolytic and ligninolytic. The first step in the metabolism of PAHs by non-ligninolytic fungi is the oxidation of the aromatic ring by a cytochrome P450 monooxygenase to produce an arene oxide like anthracen-9-ol, which can be further methylated to 9-methoxyanthracene. Whereas the initial step in the PAHs biodegradation by ligninolytic fungi are oxidations by extracellular lignin peroxidases such as laccases, manganese peroxidases $(\mathrm{MnP})$, lignin peroxidases $(\mathrm{LiP})$ and dioxygenases, which catalyze radical formation and therefore destabilize molecular bonds, producing anthrone and anthraquinone. These reactions generate a selection of PAH-quinones and acids rather than dihydrodiols. ${ }^{11,48}$

The fungi strains isolated in this work belong to the Ascomycota phylum, which is characterized by the production of ligninolytic enzymes. ${ }^{49}$ In this study, metabolites probably generated by the action of these several enzymes were observed.

The identified metabolite $1 \mathrm{a}, 9 \mathrm{~b}$-dihydro$1 H$-cyclopropa[l]phenanthrene (Figure $2 \mathrm{a}$ ) can be originated from the transformation of fluoranthene to phenanthrene by a rearrangement after several radical reactions. Then, cyclopropane formation can occur by the 
Table 3. Common metabolites from biodegradation of fluoranthene by fungi isolated from a Brazilian tropical peat identified by GC-MS and suggested by spectra libraries (NIST 8s, Wiley 8)

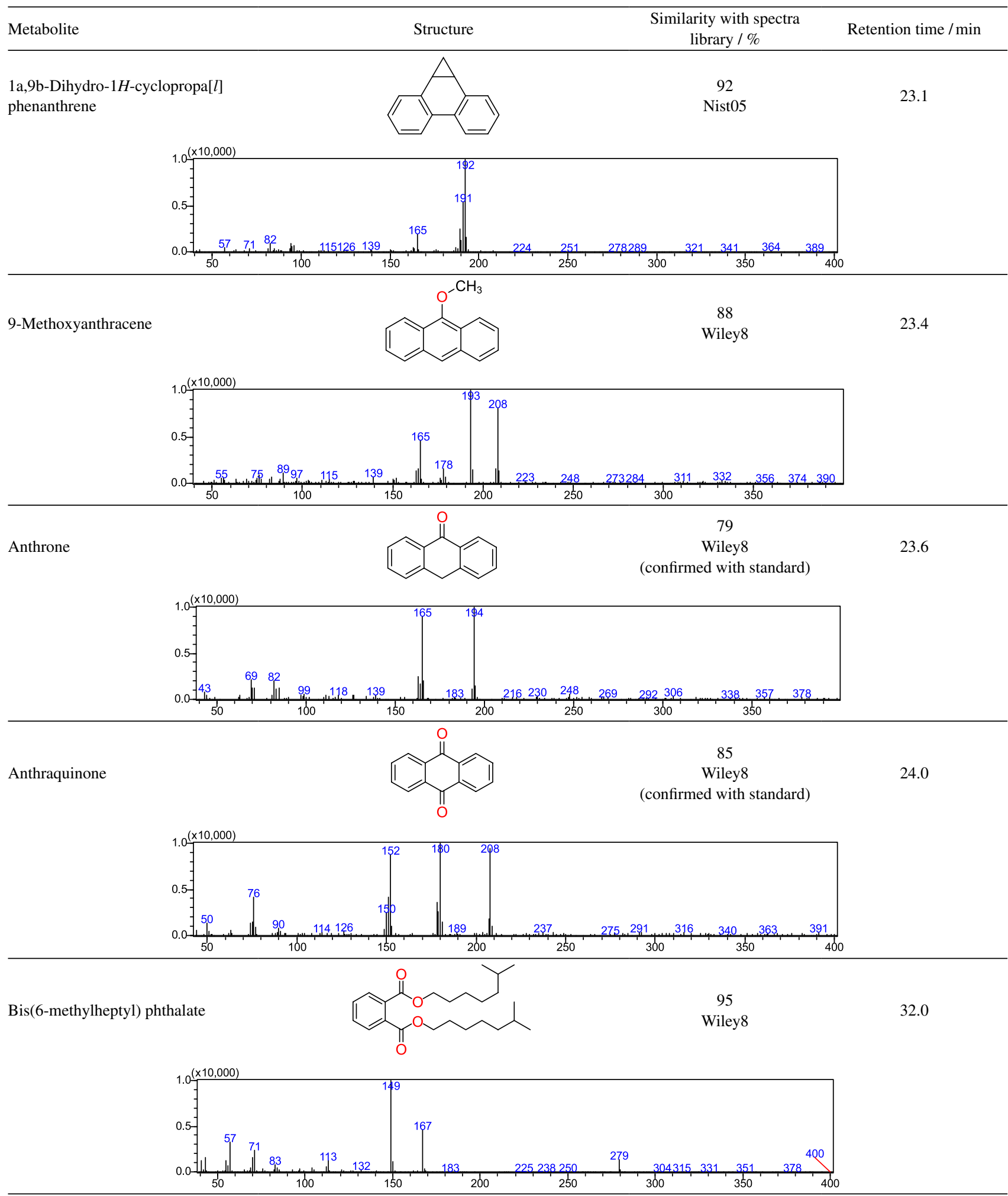

action of a cyclopropane fatty acid (CFA) synthase, which catalyzes the formation of these three-member rings from double bonds. ${ }^{50,51}$
Different metabolites of anthracene were observed in the biotransformation reactions (Figure 2b). Therefore, it was suggested that fluoranthene was converted to 


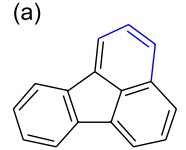

Fluoranthene

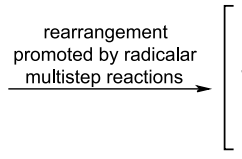

Phenanthrene

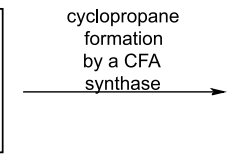

cycl

(b)

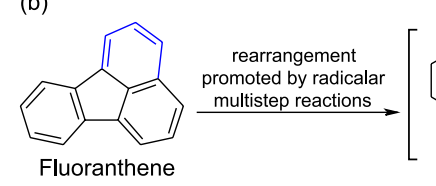

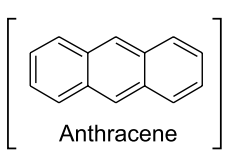

Oxidation by laccases<smiles>O=C1c2ccccc2Cc2ccccc21</smiles>

Anthrone
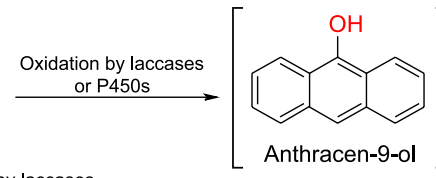

Anthracen-9-ol $\stackrel{\text { methyltransferase }}{\longrightarrow}$

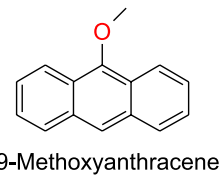

9-Methoxyanthracene<smiles>O=C1c2ccccc2C(=O)c2ccccc21</smiles>

Anthaquinone

$\downarrow$ Multistep reaction

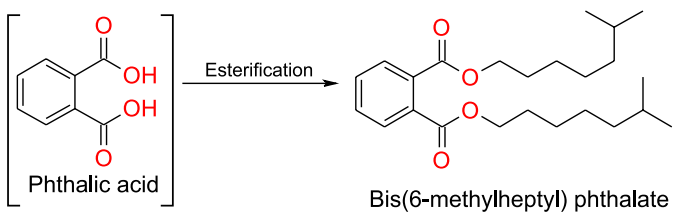

Figure 2. Proposal of fluoranthene biodegradation pathway for production of the identified metabolites.

anthracene by a multistep reaction. Then, this intermediate was converted to anthracen-9-ol by a hydroxylation reaction that can occur by the action of a laccase, ${ }^{52,53}$ or a cytochrome $\mathrm{P} 450,{ }^{54}$ followed by a methylation reaction by a methyl transferase. ${ }^{55}$ These radical reactions can also produce anthrone and anthraquinone, as observed in other studies of anthracene biodegradation by fungi..$^{31,56}$ Moreover, enzymatic promiscuity, which is the catalysis of an unexpected reaction by an enzyme, was also a possibility. ${ }^{57}$ It is important to note that the identified compounds were not present in the employed substrate, internal standard and control experiments.

Bis(octyl)benzene-1,2-dicarboxylate was also observed (Figure 3b). A study showed that phthalate esters are intermediate metabolites of fused-ring PAHs found in fossil fuels, including fluoranthene. ${ }^{58}$ Phthalic acid was suggested as a probable intermediate, since the phthalate ester identified presented a long aliphatic chain, supporting the specific characteristic of these microorganisms of accumulating aliphatic metabolites. It is noteworthy that phthalic acid and its derivatives have been identified as biodegradation metabolites of fluoranthene and others PAHs. ${ }^{14,37,44,45,59}$

A proportionality between the formation of bis(octyl) benzene-1,2-dicarboxylate and the biodegradation percentual was observed for fungal cultures for longer incubation periods. The strains that provided the more efficient fluoranthene biodegradation also produced the highest concentrations of bis(octyl)benzene-1,2-dicarboxylate (Figure 3). It is also important to note that the control experiments showed that this compound was not a significant contamination from any employed solvent or material. Moreover, further experiments should be performed to confirm the nature and origin of the observed phthalate.

Phthalic acid is the final metabolite of the fluoranthene pathway, as described by different authors..$^{14,44,45,59}$ Unfortunately, this compound was not identified as a common metabolite under the experimental procedures of this study, this substance was detected only in the form of its derivative bis(octyl)benzene-1,2-dicarboxylate. The total biodegradation of this metabolite may occur in longer reaction periods.

In general, the metabolites structures resulted in the production of molecules with higher aqueous solubility than fluoranthene, obtaining compounds more easily excreted that may be used as carbon and energy sources by other microorganisms.

\section{Conclusions}

The peat environment provided interesting fungi strains capable of degrading fluoranthene and probably other persistent organic pollutants. The three isolated fungi (Penicillium sp. AC-1, Penicillium sp. AC-6, and Fusarium sp. AC-7) degraded fluoranthene, showing the potential of these fungal strains, particularly in the initial steps of fluoranthene biodegradation, for environmental 


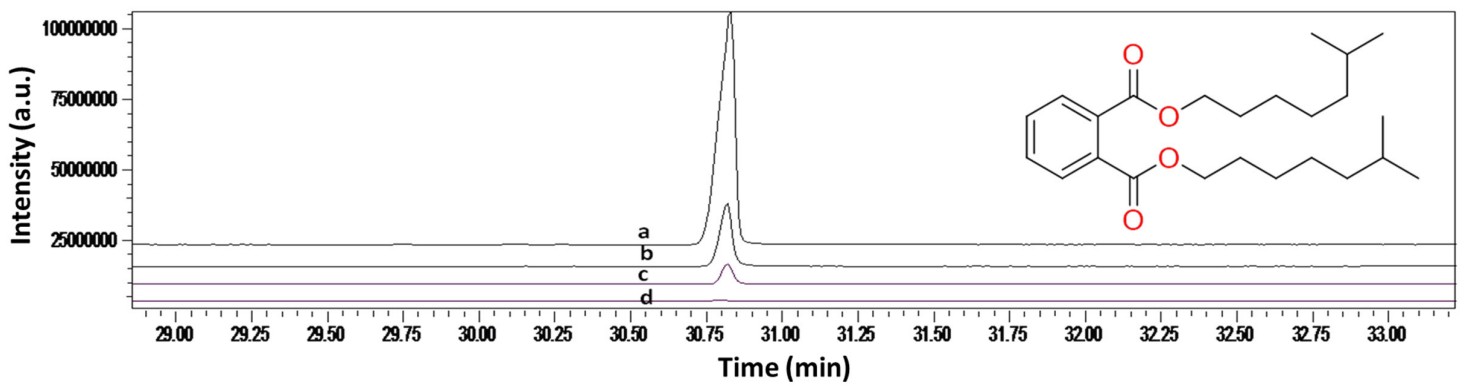

Figure 3. GC-MS chromatograms of the bis(octyl)benzene-1,2-dicarboxylate metabolite for (a) Penicillium sp. AC-1, (b) Penicillium sp. AC-6, (c) Fusarium sp. AC-7, and (d) control without the presence of fluoranthene, after incubation for 28 days.

decontamination. In addition, more information is required to obtain a better understanding of the biodiversity of the microbiota from Santo Amaro das Brotas peat. In further studies, mechanistic and enzymatic pathways should be approached for an expanded visualization of the biodegradation pathway of fluoranthene.

\section{Acknowledgments}

The financial support for this work was provided by the Brazilian National Council for Scientific and Technological Development (CNPq, grant 558062/2009-1), Research and Technological Innovation Support Foundation of the State of Sergipe (FAPITEC, grant 01920300723/201-1) and São Paulo Research Foundation (FAPESP, grants 2016/20155-7 and 2019/07654-2). WGB thanks CNPq (grant 141656/20140 ) and FAPESP (grant 2017/19721-0) for his doctorate and post-doctorate scholarships, respectively. ACFSG also thanks $\mathrm{CNPq}$ and Coordination for the Improvement of Higher Education Personnel (CAPES), code 001.

\section{Author Contributions}

Anuska C. F. S. Garcia was responsible for conceptualization, data curation, formal analysis, investigation, methodology, software, validation, visualization, writing original draft; Willian G. Birolli for conceptualization, formal analysis, investigation, methodology, visualization, writing original draft, writing-review and editing; Bruno R. Araújo for conceptualization, formal analysis, investigation, methodology, visualization; Carla G. Marques for resources, visualization, methodology; Antônio M. Barbosa-Junior for resources, visualization, methodology; Leandro E. C. Diniz for resources, visualization, methodology; André L. M. Porto for conceptualization, methodology, funding acquisition, project administration, resources, visualization, writing-review and editing; Luciane P. C. Romão for conceptualization, methodology, funding acquisition, project administration, resources, visualization, writing-review and editing.

\section{References}

1. Zhang, X. Y.; Yu, T.; Li, X.; Yao, J. Q.; Liu, W. G.; Chang, S. L.; Chen, Y. G.; Crit. Rev. Environ. Sci. Technol. 2019, 49, 1425.

2. Ferreira, R. S.; Nunes, C. R. O.; Souza, M. O.; Canela, M. C.; J. Braz. Chem. Soc. 2021, 32, 618.

3. United States Environmental Protection Agency (USEPA); Priority Pollutant List; https://www.epa.gov/sites/production/ files/2015-09/documents/priority-pollutant-list-epa.pdf, accessed in May 2021.

4. Ali, M. U.; Siyi, L. Y.; Yousaf, B.; Abbas, Q.; Hameed, R.; Zheng, C. M.; Kuang, X. X.; Wong, M. H.; Crit. Rev. Environ. Sci. Technol. 2021, 51, 857.

5. Guo, W. J.; Pan, B. H.; Sakkiah, S.; Yavas, G.; Ge, W. G.; Zou, W.; Tong, W. D.; Hong, H. X.; Int. J. Environ. Res. Public Health 2019, 16, 29.

6. Seo, J. S.; Keum, Y. S.; Li, Q. X.; Int. J. Environ. Res. Public Health 2009, 6, 278.

7. Kumar, S.; Upadhayay, S. K.; Kumari, B.; Tiwari, S.; Singh, S. N.; Singh, P. K.; Bioresour. Technol. 2011, 102, 3709.

8. Mishra, S.; Singh, S. N.; Pande, V.; Bioresour. Technol. 2014, 164, 299.

9. Dorea, H. S.; Bispo, J. R. L.; Aragao, K. A. S.; Cunha, B. B.; Navickiene, S.; Alves, J. P. H.; Romao, L. P. C.; Garcia, C. A. B.; Microchem. J. 2007, 85, 234.

10. Gitipour, S.; Sorial, G. A.; Ghasemi, S.; Bazyari, M.; Environ. Monit. Assess. 2018, 190, 546.

11. Haritash, A. K.; Kaushik, C. P.; J. Hazard. Mater. 2009, $169,1$.

12. Lu, J.; Guo, C. L.; Zhang, M. L.; Lu, G. N.; Dang, Z.; Int. Biodeterior. Biodegrad. 2014, 87, 75.

13. Peng, X.; Xu, P. F.; Du, H.; Tang, Y.; Meng, Y.; Yuan, L.; Sheng, L. P.; Appl. Ecol. Environ. Res. 2018, 16, 6419.

14. Nzila, A.; Environ. Pollut. 2018, 239, 788.

15. Wang, S. Z.; Nomura, N.; Nakajima, T.; Uchiyama, H.; J. Biosci. Bioeng. 2012, 113, 624.

16. Hadibarata, T.; Yuniarto, A.; Biocatal. Agric. Biotechnol. 2020, $28,101717$.

17. Garcia, A.; Araujo, B. R.; Birolli, W. G.; Marques, C. G.; Diniz, L. E. C.; Barbosa, A. M.; Porto, A. L. M.; Romao, L. P. C.; Appl. Biochem. Biotechnol. 2019, 188, 1168. 
18. Mocali, S.; Benedetti, A.; Res. Microbiol. 2010, 161, 497.

19. Narendran, R.; Kathiresan, K.; Sathishkumar, R. S.; Kayalvizhi, K.; Sundaramanickam, A.; Biocatal. Agric. Biotechnol. 2019, 19, 101100.

20. European Commission; Communication from the Parliament, the Council, the European Economic and Social Committee and the Comitte of the Regions; https://ec.europa.eu/info/ sites/default/files/communication-annex-eu-biodiversitystrategy-2030_en.pdf, accessed in May 2021.

21. Leifeld, J.; Menichetti, L.; Nat. Commun. 2018, 9, 1071.

22. Sanches, S. M.; de Campos, S. X.; Vieira, E. M.; Ecletica Quim. 2007, 32, 49.

23. Romão, L. P. C.; Lead, J. R.; Rocha, J. C.; de Oliveira, L. C.; Rosa, A. H.; Mendonça, A. G. R.; Ribeiro, A. S.; J. Braz. Chem. Soc. 2007, 18, 714.

24. Costa, A. S.; Romão, L. P. C.; Araujo, B. R.; Lucas, S. C. O.; Maciel, S. T. A.; Wisniewski, A.; Alexandre, M. R.; Bioresour. Technol. 2012, 105, 31.

25. Cunha, G. D.; Romão, L. P. C.; Santos, M. C.; Araujo, B. R.; Navickiene, S.; de Padua, V. L.; Bioresour. Technol. 2010, 101, 3345.

26. Andersen, R.; Chapman, S. J.; Artz, R. R. E.; Soil Biol. Biochem. 2013, 57, 979.

27. Empresa Brasileira de Pesquisa Agropecuária (EMBRAPA), Manual de Métodos de Análise de Solo, 1997, available at https://www.agencia.cnptia.embrapa.br/Repositorio/Manua 1+de+Metodos_000fzvhotqk02wx5ok0q43a0ram31wtr.pdf, accessed in April 2021.

28. Madueno, L.; Coppotelli, B. M.; Alvarez, H. M.; Morelli, I. S.; Int. Biodeterior. Biodegrad. 2011, 65, 345.

29. Biomatters; Geneious Prime, 6.1.8; Geneious, New Zealand, 2013.

30. Tamura, K.; Stecher, G.; Peterson, D.; Filipski, A.; Kumar, S.; Molecular Evolutionary Genetics Analysis, 6.0; Pennsylvania State University, USA, 2013.

31. Birolli, W. G.; Santos, D. D.; Alvarenga, N.; Garcia, A.; Romao, L. P. C.; Porto, A. L. M.; Mar. Pollut. Bull. 2018, 129, 525.

32. dos Anjos, C. S.; Birolli, W. G.; Porto, A. L. M.; J. Braz. Chem. Soc. 2020, 31, 1654.

33. Ebeling, A. G.; dos Anjos, L. H. C.; Perez, D. V.; Pereira, M. G.; Gomes, F. W. D.; Rev. Bras. Cienc. Solo 2011, 35, 325.

34. Bragazza, L.; Siffi, C.; Iacumin, P.; Gerdol, R.; Soil Biol. Biochem. 2007, 39, 257.

35. Cerqueira, V. S.; Hollenbach, E. B.; Maboni, F.; Camargo, F. A. O.; Peralba, M. D. R.; Bento, F. M.; World J. Microbiol. Biotechnol. 2012, 28, 1203.

36. Aranda, E.; Godoy, P.; Reina, R.; Badia-Fabregat, M.; Rosell, M.; Marco-Urrea, E.; Garcia-Romera, I.; Int. Biodeterior. Biodegrad. 2017, 122, 141.

37. Jové, P.; Olivella, M. A.; Camarero, S.; Caixach, J.; Planas, C.;
Cano, L.; de las Heras, F. X.; J. Environ. Sci. Health, Part A: Toxic/Hazard. Subst. Environ. Eng. 2016, 51, 70.

38. Wu, Y.-R.; Luo, Z.-H.; Vrijmoed, L. L. P.; Bioresour. Technol. 2010, 101, 9666.

39. Zhao, O. Y.; Feng, S. D.; Jia, H. B.; Zhang, X. N.; Wei, S.; Wei, W.; Yang, Z. X.; Li, Y. L.; Polycyclic Aromat. Compd. 2018, 38, 32.

40. Syed, K.; Porollo, A.; Lam, Y. W.; Grimmett, P. E.; Yadav, J. S.; Appl. Environ. Microbiol. 2013, 79, 2692.

41. Lee, A. H.; Lee, H.; Heo, Y. M.; Lim, Y. W.; Kim, C. M.; Kim, G. H.; Chang, W.; Kim, J. J.; Bioprocess Biosyst. Eng. 2020, 43, 767.

42. Park, H.; Min, B.; Jang, Y.; Kim, J.; Lipzen, A.; Sharma, A.; Andreopoulos, B.; Johnson, J.; Riley, R.; Spatafora, J. W.; Henrissat, B.; Kim, K. H.; Grigoriev, I. V.; Kim, J. J.; Choi, I. G.; Appl. Microbiol. Biotechnol. 2019, 103, 8145.

43. Alvarenga, N.; Birolli, W. G.; Seleghim, M. H. R.; Porto, A. L. M.; Chemosphere 2014, 117, 47.

44. Cao, J. W.; Lai, Q. L.; Yuan, J.; Shao, Z. Z.; Sci. Rep. 2015, 5, 7741.

45. Rehmann, K.; Hertkorn, N.; Kettrup, A. A.; Microbiology 2001, 147, 2783.

46. Hadibarata, T.; Kristanti, R. A.; Agric. Agric. Sci. Procedia 2015, 3, 45.

47. Wirasnita, R.; Hadibarata, T.; Pedosphere 2016, 26, 49.

48. Bamforth, S. M.; Singleton, I.; J. Chem. Technol. Biotechnol. 2005, 80, 723 .

49. Blanchette, R. A.; Annu. Rev. Phytopathol. 1991, 29, 381.

50. Okada, S.; Taylor, M.; Zhou, X. R.; Naim, F.; Marshall, D.; Blanksby, S. J.; Singh, S. P.; Wood, C. C.; Front. Plant Sci. 2020, 11, 30 .

51. Bianco, C. M.; Frohlich, K. S.; Vanderpool, C. K.; J. Bacteriol. 2019, 201, e00461-19.

52. Ike, P. T. L.; Moreira, A. C.; de Almeida, F. G.; Ferreira, D.; Birolli, W. G.; Porto, A. L. M.; Souza, D. H. F.; Springerplus 2015, 4, 654.

53. Ike, P. T. L.; Birolli, W. G.; dos Santos, D. M.; Porto, A. L. M.; Souza, D. H. F.; Environ. Sci. Pollut. Res. 2019, 26, 8675.

54. Reed, L.; Arlt, V. M.; Phillips, D. H.; Carcinogenesis 2018, 39 , 851.

55. Hevel, J. M.; Price, O. M.; Methods 2020, 175, 3.

56. Teng, C.; Wu, S. M.; Gong, G. Y.; Food Control 2019, 105, 219.

57. Birolli, W. G.; Porto, A. L. M.; Fonseca, L. P.; Bioresour. Technol. 2020, 297, 122441.

58. Eaton, R. W. J.; Bacteriol. 2001, 183, 3689.

59. Peng, R. H.; Xiong, A. S.; Xue, Y.; Fu, X. Y.; Gao, F.; Zhao, W.; Tian, Y. S.; Yao, Q. H.; FEMS Microbiol. Rev. 2008, 32, 927.

Submitted: February 17, 2021

Published online: May 27, 2021 